WellBeing International

WBI Studies Repository

$2-1978$

\title{
Quantitative Analyses of the Ontogeny of Predatory Behaviour in Coyotes, Canis Latrans
}

Louis E. Vincent

University of Colorado

Marc Bekoff

University of Colorado

Follow this and additional works at: https://www.wellbeingintlstudiesrepository.org/acwp_ena

Part of the Animal Studies Commons, Behavior and Ethology Commons, and the Comparative Psychology Commons

\section{Recommended Citation}

Vincent, L. E., \& Bekoff, M. (1978). Quantitative analyses of the ontogeny of predatory behaviour in coyotes, Canis latrans. Animal Behaviour, 26, 225-231.

This material is brought to you for free and open access by WellBeing International. It has been accepted for inclusion by an authorized administrator of the WBI Studies Repository. For more information, please contact wbisr-info@wellbeingintl.org.

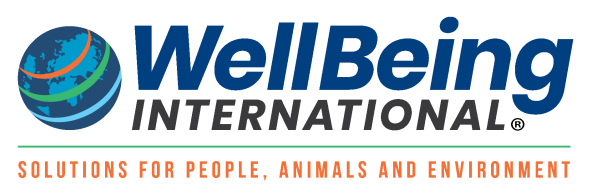




\title{
Quantitative Analyses of the Ontogeny of Predatory Behaviour in Coyotes, Canis Latrans
}

\author{
Louis E. Vincent and Marc Bekoff \\ University of Colorado
}

\begin{abstract}
$\underline{\text { ABSTRACT }}$
Four infant coyotes (Canis latrans) were studied in order to describe quantitatively the development of predatory behaviour. Our results indicated that prior play and agonistic experience had virtually no effect on later predatory success. Also, there was no relationship between an individual's social rank and its prey-killing ability. Latency to kill was shortened when animals were tested in, pair and hunger level was not related to latency to kill. The results are discussed with respect to current 'functionalist' theories of play behaviour and Leyhausen's concept of the relative hierarchy of moods. The practice theory of play should be reconsidered in light of the results of this and other recent studies.
\end{abstract}

Studies of predatory behaviour have contributed significantly to achieving a greater understanding of behavioural mechanism in general. For example, Leyhausen $(1956,1965)$ developed his theory of the function of the relative hierarchy of moods from detailed descriptions of prey-catching and killing in the Felidae. Eisenberg \& Leyhausen (1972), examined predatory behaviour in representatives of 49 mammalian genera and discussed the relationship between the evolution and ecology of a given species and its techniques of killing prey. Furthermore, numerous studies of prey-killing in a single mammalian (and other) species or within a group of closely related species have been performed (e.g. Eibl-Eibesfeldt 1956, 1961, 1963; Wüstehube 1960; Ewer 1963, 1968; Fox 1969; Rasa 1973).

In canids, qualitative analyses of the development of predatory behaviour have been conducted on a few species (Fox 1969). However both the development of predatory behaviour in coyotes as well as the technique of prey-killing by adults (White 1973), is poorly understood, and further information on this subject is needed by those interested in behavioural evolution or conservation and management (Bekoff 1977a).

The purpose of the present investigation was to expand upon present knowledge and to quantify ontogenetic and motivational aspects of prey-killing by coyotes in light of hypotheses advanced by workers studying other species. The following questions were asked: (1) Do high-ranking individuals develop into 'killers' faster than low-ranking individuals (Leyhausen 1965; Rasa 1973)? (2) What is the influence of prior playful and agonistic experience with conspecifics on later success in prey-killing? (3) Does the presence of conspecifics during confrontation with prey, hunger level or level of physical development affect latency to kill or individual success in prey-killing? There are no quantitative data 
available for canids that relate to these problems and also, the question of what actually is 'acquired' during play remains unanswered (Schaller 1972; Bekoff 1976).

\section{Methods}

Four coyote pup comprising one litter were removed from an underground den at the Ethology Group's enclosure $(12 \times 20 \mathrm{~m})$ when they were 20 days of age. For the duration of this study the pups were housed in a smaller indoor enclosure $(2 \times 2 \mathrm{~m})$ that had a dirt and woodchip floor. From the day of removal until they were able to lap and eat 'mushy' food (day 24), the animals were hand-reared by bottle feeding them a mixture of liquefied Esbilac (Borden's) and corn syrup. Between 31 and 45 days of age, they were all fed milk and a mixture of Purina Dog Chow in separate pans. All animals were treated similarly throughout the course of the study. The litter was observed $12 \mathrm{hr}$ daily from day 21 to 35 (180 h). Data were either hand-written, read into a cassette recorder, or recorded on a Sony AVC-3400 video-tape recorder using a pre-established code (Bekoff 1972, 1974). Physical measurements (weight in grams, body length excluding tail in centimetres, tail length, length of right hind foot and length of the right ear) were recorded every other day. A linear regression analysis of weight was used to calculate the growth rate.

At 35 days of age, all individual were given their first experience with prey (adult, black or white Mus musculus). Colour, sex, and size of prey were kept constant on each day of testing. On day 35, both live and dead mice were presented simultaneously to each animal individually in the indoor cage. Prey-killing trial lasted $10 \mathrm{~min}$. If, after $10 \mathrm{~min}$ the coyote failed to kill the mouse, both coyote and mouse were removed. Observations were read directly into a cassette or recorded on video tape, and an exact timebase was maintained.

From days 36 to 45 an additional 10 prey-killing trials were conducted. Once again, each animal was tested individually but only live mice were presented. During these trials, the effect of hunger level, expressed as time since last feeding (varying from 2 to $18 \mathrm{~h}$ over the 10 trials but kept constant for all the animal on any given day) on latency to kill, was measured. In addition, pairs of animals were also tested to determine if there would be any effect on predatory behaviour.

During prey-killing trials a total of 28 actions was recorded (see below and Fig. 1). Each action was assigned a two-digit code and sequences were analysed using a CDC 6400 digital computer.

\section{Results}

Individual measures of rank, growth rate weight at 34 days of age, and frequencies of play, agonistic interactions, and play-solicits (see Bekoff 1974) prior to the animal's first experience with prey are presented in Table I. Success in prey-killing, measured as the percent of trial in which a kill was made, is also presented in Table II for comparison. Calculation of Pearson product-moment correlation coefficients between each of the above variables and prey-killing success showed that only the frequency of playsolicits was significantly correlated with later prey-killing success $(r=0.91 d f=3, P<0.05)$. Play bouts were preceded (solicited) by play-solicits $88.6 \%$ of the time and the individuals were successful in soliciting play from a littermate only $29.1 \%$ of the time. (These data are in full agreement with those reported by Bekoff (1974), who found that $90 \%$ of all play bouts had previously been solicited and success rate to be $28 \%$.)

The frequencies of occurrence of specific prey-killing actions head-shake (HS), bite (BI), pounce (PO), and paw (PW), both in play and during agonistic interactions are compared to prey-killing success in Table II. Calculation of Pearson product-moment correlation coefficients between these frequencies and eventual prey-killing success showed that only the frequency of pounce in play was significantly 
correlated with later prey-killing success $(r=0.99, d f=3, P<0.01)$, although pounce occurred very infrequently either during play or agonistic interactions. For the other three actions, HS, BI and PW, the correlations were all positive, though not significant, for play and non-significantly negative for agontstic behaviour. The effect of hunger level on latency to kill was not significant $(r=-0.05, d f=16, P>0.05)$.

Latency to kill was measured in each individual prey-killing trial and compared to latency to kill for the same individual in paired prey-killing trials. Overall, the mean latency in individual trials was 5.47 min and for paired trials the latency to kill was $2.68 \mathrm{~min}$. When the latencies in the two situations were compared for each individual, the differences were found to be significant $(t=2 \cdot 65, d f=19, P<0.02)$.

Table I. Comparison of Morphological and Behavioural Data, Prior to Exposure to Prey, with Frey-killing Success During Individual Trials

\begin{tabular}{|c|c|c|c|c|c|c|}
\hline Sex & Rank & $\begin{array}{c}\text { Growth rate (g/day) (and } \\
\text { weight at } 34 \text { days)* }\end{array}$ & $\begin{array}{c}\text { Frequency of } \\
\text { playt }\end{array}$ & $\begin{array}{l}\text { Frequency of } \\
\text { aggression }\end{array}$ & $\begin{array}{l}\text { Frequency of } \\
\text { play-solicits }\end{array}$ & $\begin{array}{c}\text { Success in } \\
\text { Prey-killing (\%) }\end{array}$ \\
\hline $\begin{array}{l}\text { Male } \\
\left(M_{1}\right)\end{array}$ & $0 \cdot 86(1) \ddagger$ & $\begin{array}{c}35 \cdot 4 \\
(1350)\end{array}$ & 78 & 110 & 98 & $18 \cdot 2$ \\
\hline $\begin{array}{l}\text { Male } \\
\left(M_{2}\right)\end{array}$ & $0.82(2)$ & $\begin{array}{c}43 \cdot 9 \\
(1425)\end{array}$ & 77 & 131 & 104 & $27 \cdot 3$ \\
\hline $\begin{array}{l}\text { Female } \\
\left(F_{1}\right)\end{array}$ & $0 \cdot 43(3)$ & $\begin{array}{c}24 \cdot 2 \\
(1125)\end{array}$ & 67 & 108 & 86 & 0.0 \\
\hline $\begin{array}{l}\text { Female } \\
\left(F_{2}\right)\end{array}$ & $0.04(4)$ & $\begin{array}{c}40 \cdot 1 \\
(1200)\end{array}$ & 60 & 121 & 114 & $100 \cdot 0$ \\
\hline
\end{tabular}

*Individual were weighed every other day beginning on day 20.

†Based on $180 \mathrm{~h}$ of observation.

łrank = number of agonistic interaction won by the individual divided by total number of agonistic interactions with outcome in which the individual participated. Numbers in parentheses indicate assigned rank. Linearity was confirmed using Landau's measure (Chase 1974) .

Table II. Comparison of Frequency of Prey-killing Actions in Different Contests with Prey-killing Success During Individual Trials

\begin{tabular}{|c|c|c|c|c|c|c|c|c|c|}
\hline \multirow[b]{2}{*}{ Sex } & \multicolumn{2}{|c|}{ Head-shaking } & \multicolumn{2}{|c|}{ Biting } & \multicolumn{2}{|c|}{ Pouncing } & \multicolumn{2}{|c|}{ Pawing } & \multirow{2}{*}{$\begin{array}{c}\text { Success in } \\
\text { prey-killing } \\
(\%)\end{array}$} \\
\hline & $\mathbf{A g}^{*}$ & Play & $\mathrm{Ag}$ & Play & $\mathrm{Ag}$ & Play & $\mathrm{Ag}$ & Play & \\
\hline $\mathrm{M}_{1}$ & 4 & 3 & 50 & 45 & 0 & 1 & 6 & 10 & $18 \cdot 2$ \\
\hline$M_{2}$ & 13 & 15 & 70 & 58 & 1 & 1 & 6 & 16 & $27 \cdot 3$ \\
\hline$F_{1}$ & 11 & 3 & 48 & 37 & 0 & 0 & 0 & 7 & 0.0 \\
\hline$F_{2}$ & 2 & 5 & 27 & 46 & 0 & 4 & 2 & 17 & $100 \cdot 0$ \\
\hline $\begin{array}{l}\text { Correlation with prey- } \\
\text { killing success }\end{array}$ & -0.66 & +0.02 & -0.68 & +0.21 & $-0 \cdot 13$ & $+0.99 \dagger$ & -0.09 & +0.45 & \\
\hline
\end{tabular}

${ }^{*} \mathrm{Ag}=$ agonistic interactions.

$\dagger P<0.01$.

\section{Movement as a Releaser for Prey-Killing and the Predatory Sequence}

All pups oriented and showed heightened attention to a moving mouse. In one instance, a pup was chasing the moving mouse when it happened to run past the dead one (day 35). It picked up the dead 
mouse but continued to chase the moving prey while clinging to the dead mouse with its teeth Only when the live mouse stopped moving did the coyote pup give up the chase and begin to cat the dead mouse. When the other mouse began moving again the pup left the partially eaten dead mouse and began chasing the prey. The pup subsequently killed the mouse, took it to the spot where it had left the dead mouse, and finished eating the first mouse before eating the second.

Fig. I. A composite predatory sequence from observations of 15 individual trials. The numbers represent transition probabilities in per cent. The listed behaviours occurred more than 10 times except for CL (4 times). OR: orient; AP: approach; FO: follow; AB: attempted bite; BI: bite; LF: lift; HS: head-shake while biting; DR: drop; ET: eat; WD: withdraw; SN: sniff; TS: toss; PW: paw or paw stab; PO: pounce at prey; CR: carry; CL: circles; MD: mouse dead. Other actions observed included approach/withdraw, stalking approach, chase, nose stab and prodding prey with the nose, licking, pinning prey, and play-soliciting.

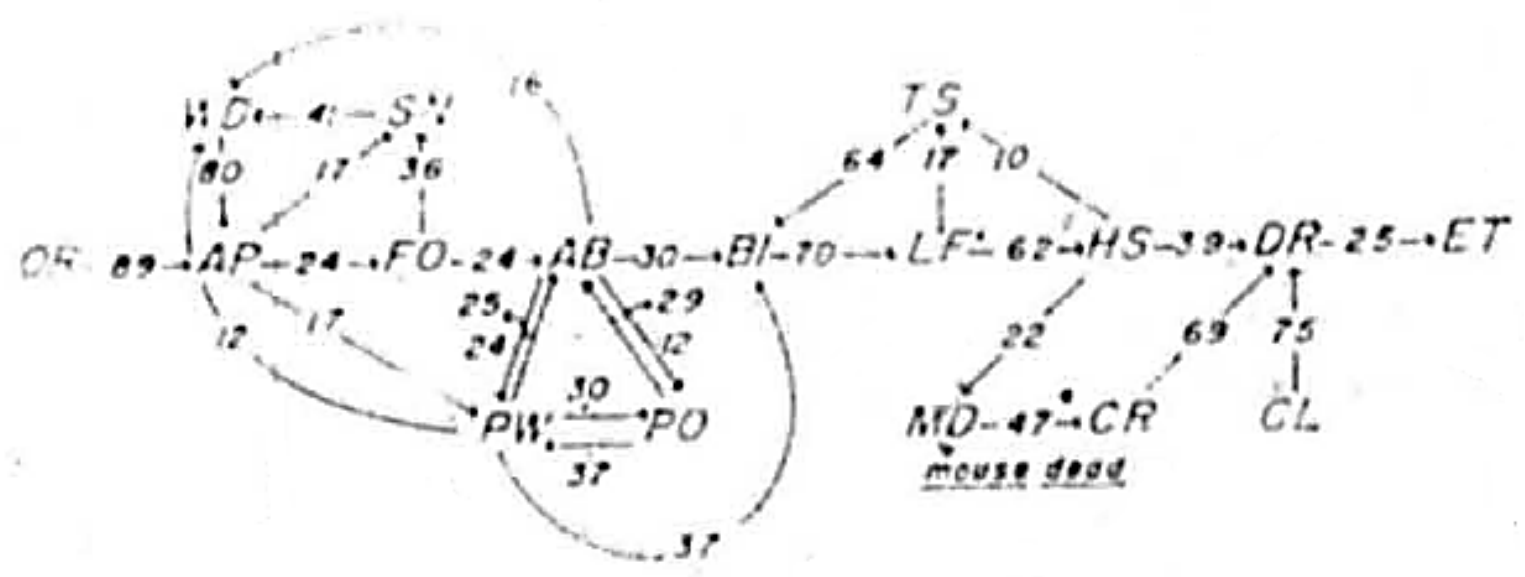

A composite prey-killing sequence is presented in Fig. I. There were no apparent differences between males and females, so all 15 successful individual sequences were considered together without regard for the sex of the animal. Sequences in which the prey were killed began with an almost immediate orientation (OR) to the mouse followed by an approach (AP). At this point, the mouse usually moved away and the coyote pup followed it. Typically, the coyote would then sniff (SN) the mouse, withdraw (WD) and then approach once again. This sequence might be repeated several times before following (FO) led to an attempted bite (AB). Attempted bites led to bite (BI) and also a cycle of pawing (PW) and pouncing (PO) occurred frequently before the first bite was delivered. Bites led to lift (LF) then headshake (HS), followed by, tossing (TS) or dropping (DR) the mouse. The cycle of bite, life, head shake, and toss or drop was usually repeated several times until either a bite or headshake resulted in the death (MD) of the mouse. Head-shaking led to death nine times while bite alone resulted in death only six times. The dead mouse was then carried (CR) around the enclosure to a corner (as far as possible from the observer) where it was dropped (DR) and eaten (ET). Sometimes the animal circled (CL) with the mouse in its mouth before dropping and eating it.

Sequences in which the mouse was killed were very similar to one another but by no means did the coyote always kill when presented with a mouse (Table II). One female $\left(F_{2}\right)$ killed in every individual trial while $F_{1}$ did not kill at all until she was paired with a littermate. One male $\left(M_{1}\right)$ did not kill in the individual trials until he was 43 days of age, but killed in all subsequent individual trials. The other male $\left(M_{2}\right)$ killed only at 36 and 45 days of age when tested individually. $M_{2}$ showed consistency in latency to kill: 6.56 min on day 36 and $6.58 \mathrm{~min}$ on day 45 . The other two animals had latencies that were quite variable: $F_{2}$ range $=1.15$ to $8.03 \mathrm{~min}$ and $\mathrm{M}_{1}$, range $=1.10$ to $12.02 \mathrm{~min}$. No particular pattern could be discerned .with respect to these variations. 
Action patterns used while eating were also examined. Typically, the animals would lie down next to the mouse after dropping it. They would then sniff, lick (LI) and nibble the mouse all over before holding it down with one or both forepaws on its hindend. With the rear of the mouse anchored in this fashion the coyote would begin feeding on the anterior end, mainly using its carnassials.

The anterior feeding orientation and use of the forepaws were observed on the second and all subsequent experiences of eating prey in all four animals. One female $\left(F_{2}\right)$ showed this pattern in her first encounter with prey, however the others seemed to have to learn it. For example, on their first encounter with prey, these latter animals all began eating from the posterior end of the mouse without using their paws to secure it to the floor. They would stop eating and sniff, lick and nibble the mouse all over. When they began eating once again, they would begin more anteriorily. The cycle of eat, stop, sniff, lick, and nibble continued until they had worked their way to the mouse's head. Perhaps lie of the hair was an important directional cue (e.g. Leyhausen 1965. Ewer 1968). One the pups began to eat from the anterior end, they continued to do so without interruption. By chance, it seemed one or both of the forepaws came in contact with the mouse and were incidentally used to hold down the hindquarters of the mouse in the typical feeding posture described above. Once they achieved this posture, the pup systematically devoured the mouse in an anterior-posterior direction, using its carnassials to crush bone and cut pieces of skin and meat from the body.

\section{Discussion}

Experience in the form of social interactions with littermates, contributed little to the development of preykilling behaviour in these coyotes. Neither the frequency of participation in play nor the frequency of agonistic interactions were significantly correlated with prey-killing success. Analyses of what the animals 'do' when they play or fight and how this may be related to later predatory success, also showed that with only one exception, the frequency of performance of action patterns from the prey-killing sequence during either play or agonistic interactions was not correlated with success in prey-killing.

The idea that play provides practice for behaviour patterns that will be needed later in life, although frequently suggested as a major 'function' of play (Groos 1898; Aldis 1975), is not well supported both in this and other studies (Wüstehube 1960; Poole 1966; Baldwin \& Baldwin 1974, 1976; Symons 1974; Bekoff 1976). Rasa (1973) has written that variations in the play repertoire of various carnivores may be attributed directly to disparities found in true prey capture but the results of this study indicate that what is done in play is not correlated with success in initial prey-killing. In addition, Schaller (1972) noted that stalking was relatively unimportant in the play of the lions he studied, but that stalking was very important in hunting. It is very possible that play experience may be useful for increasing the facility or co-ordination with which the prey-killing sequence is performed (Leybausen 1965; Eisenberg \& Leyhausen 1972; Rasa 1973; Polsky 1975a) due to general exercise that is provided by play (Fagen 1976). However, the benefits of play, with respect to the acquisition of specific social and other skills, still remain unknown (Schaller 1972; Baldwin \& Baldwin 1976; Bekoff 1976). The fact that aggression and success in preykilling were not correlated is not surprising since these two categories of behaviours probably lie within different 'motivational systems' (Eibl-Eibesfeldt 1975; Polsky 1975b).

The frequency of pounce in play and the frequency of play-solicits were significantly correlated with later success in prey-killing. However, he very low frequency of pouncing either during play or agonistic interactions argues against putting much emphasis on this correlation. The correlation between frequency of play-solicits and later success in prey-killing is not so easily explained. High frequencies of playsoliciting may be indicative of some general 'need' for physical interaction that contributes to later success as a predator. 
Social rank was not significantly correlated with killing success. This finding conflicts with the results of several other studies (Eibl-Eibesfeldt 1963; Fox 1972; Rasa 1973) in which high-ranking individuals were observed to be more successful predators than were individual of lower rank. Obviously more data are needed regarding this aspect of predatory behavior, but the results of this study point out the dangers of over-generalizing one's results both within and between species. Individual differences exist in a variety of behaviour patterns within and between wolf (Fox 1972) and coyote litters, for example (Bekoff 1977b), and to find that the relationship between rank and prey-killing ability does not hold for all litters of a given species would not be unexpected.

Movement has been postulated to be a necessary or effective releaser for prey catching and killing (EiblEibesfeldt 1956, 1963; Fox 1969). Our study supports this view. Even when already engaged in the consummatory behaviour of eating prey, prey-catching and killing patterns were readily released by another moving prey animal.

With respect to the effect of the presence of another animal on latency to kill, we found that latencies were significantly lower in paired prey-killing trials than during individual trials. Leyhausen (1965) reported that the threshold excitation for killing in felids depends on the presence of conspecifics. The mechanism for this effect appears to be based on the phenomenon of social facilitation. Although co-ordinated group prey-killing is not as common in the coyote as in some of the other more social canids (Beko 1977a), the demonstration of facilitation in prey-killing by pairs of animals opens up this 'option' for the coyote, possibly permitting it to utilize more varied food resources by taking animals larger than itself. Other canids that typically hunt alone are more successful when they hunt in pairs. Kruuk (1972) reported that single golden jackals (C. aureus) were only successful in taking down Thompson's gazelle fawns (Gazella thomsonii) $16 \%$ of the time while pairs had a success rate of $67 \%$. The fact that coyotes do occasionally hunt in pairs (or larger groups) (Bekoff 1977a; Bekoff, Hill \& Doran unpublished data) combined with their ability to compensate for reduced population density by increased litter size (Knowlton 1972) helps to explain the phenomenal success of the coyote in North America, despite intensive though often poorly managed control programmes.

The effect of hunger on killing latency was also investigated. No relationship was found for these coyotes. For felids, Leyhausen (1965) reported that hunger had no direct effect on the 'endogenous rhythmicity' of individual prey-killing actions. These results suggest that feeding and the actions associated with preycatching and killing may be motivationally unrelated in inexperienced coyotes. Indeed, the relationships between hunger and feeding (McFarland 1971; McFarland \& Sibly 1972) and among hunger feeding, and killing (Polsky 1975a,b) are rather complex. This is not to say, however that the coyote cannot learn the relationship between killing prey and procuring food. Experience cats do, in fact, kill more quickly when hungry than when they are satiated (Leyhausen 1965). Possibly, coyotes that have learned the relationship would behave similarly to the cats observed by Leyhausen. In any event the possibility that feeding and the actual killing of prey may be only weakly related should be taken into consideration by those attempting aversive conditioning in this animal (Gustavson et al. 1974; Bekoff 1975).

Our results on inexperienced coyotes differ from those reported by Fox (1969). When the three coyotes that Fox observed were 30 days old, upon their first experience with prey they immediately responded by running at the prey and seizing it around the thorax. Only one of our four subjects responded in this fashion and in another study (Bekoff \& Jamieson unpublished data) only one of six coyote pups from the same litter responded similarly. Individual differences in approach tendency and reaction to the mouse's behaviour were strikingly apparent. Infant felids also show individual variability in response to the first presentation of live prey (Leyhausen 1965). Fox also reported that during subsequent tests there was no change in response latencies or in the method of killing the prey. He reported that killing was accomplished by crushing the prey between the jaw. In the present study vigorous headshaking 
accompanied the killing bite. Since Fox does not present either detailed response times or sequence analyses, we cannot directly compare our results. However we did find large individual differences in response latencies on different days in all but one animal.

One major difference between our observations and those of Fox (1969) involve his characterization of the coyote prey-killing sequence as a "coyote play cycle'. He states that ' ... chasing and forepaw stabbing and holding of the prey and intention biting or inhibited biting persisted for varying periods, and was designed a play behavior because the prey was not killed.' However, the prey was eventually killed. The imperfectly co-ordinated attempt of an inexperienced animal should not be designated as play merely because they failed to achieve a particular (expected by the observer) goal a quickly as expected (Bekoff 1972). In the present study, play with prey by female 2 was observed in two sequences in which the prey was eventually killed. The play was preceded by play-solicits in the form of exaggerated approaches and leaps in a manner similar to that seen in play with conspecifics and inanimate objects (Bekoff 1974).

The above observations may be best explained in terms of a 'relative hierarchy of moods' within the system of predatory behaviour (Leyhausen 1965). Thus action pattern with the lowest threshold are performed first, and these appetitive actions, instead of leading directly to a consummatory behaviour (e.g. killing), may lead to other appetitive actions. Since the expected 'goal' is not attained during initial interactions with the prey the activity can easily be interpreted a play when in fact it is not (see Ewer 1967, p. 74 for a discussion of the necessity for studying processes and not end results). As the animal perform a chain of appetitive actions, the threshold for subsequent behaviours is lowered, due to internal and/or external factors, and killing eventually is achieved. Therefore the initial behaviour may be necessary for the 'goal' to be achieved and in this sense do not necessarily represent play.

\section{Acknowledgment.}

We would like to thank Judy Diamond, Jim Cribari, Kent Scudder, and Harriet Hill for help with observations and animal care. Christen Wemmer and Olwen Williams provided helpful comments on an earlier draft of this paper and Gerry Corcoran and Jeffry B. Mitton aided with the computer analyses. Ms Dorothea Slater and Fay Tracy kindly typed the manuscript. This study was supported by a Faculty Research Initiation Fellowship and a Biomedical Grant from the University of Colorado to M. B.

\section{REFERENCES}

Aldis, O. 1975. Play Fighting. New York; Academic Press

Baldwin, J. D. \& Baldwin, J. I. 1974. Exploration and social play in squirrel monkeys. Am. Zool. 14, 303315.

Baldwin, J. D. \& Baldwin, J. I. 1976. Effects of food ecology on social play: A laboratory simulation. $Z$. Tierpsychol., 40, 1-14.

Bekoff, M. 1972. The development of social interaction, play, and metacommunication in mammals: An ethological perspective. Q. Rev. Biol., 41, 412-434.

Bekoff, M. 1974. Social play and play-soliciting by infant canid . Am. Zool., 14, 323-340.

Bekoff, M. 1975. Predation and aversive condition in coyotes. Science, N. Y. 181, 1096.

Bekoff, M. 1976b. Social Play: Problem and perspectives.

Bekoff M. 1976. Social play. Problems and perspectives. In: Perspectives in Ethology. Vol. 2 (Ed. by P. P. G. Bateson \& P. H. Klopfer), pp. 165-188. New York: Plenum Pub. Co.

Bekoff, M. 1977a. Canis latrans Say. Mammal. Species No. 79, 1-9.'

Bekoff, M. 1977b. Mammalian dispersal and the ontogeny of individual behavioral phenotypes. Am. Nat., 111, 715-732.

Chase, J. D. 1974. Models of hierarchy formation in animal societies. Behav. Sci., 19, 374-382. 
Eibl-Eibesfeldt, I. 1956. Angeborenes and Erworbenes in der Technik de Beutetötens (Versuche am Iltis, Putorius putorius L.). Z. Säugetierk., 31, 135-137.

Eibl-Eibesfeldt, I. 1961. The interactions of unlearned behaviour patterns and learning in animal. In: Brain Mechanisms and Learning (Ed. by J. F. Delafresnaye) pp. 53-73. Oxford: Oxford Unversity Press.

Eibl-Eibesfeldt, I. 1963. Angeborenes und Erworbenes im Verhalten einiger Säuger. Z. Tierpsychol., 20 59-93.

Eibi-Eibesfeldt, I. 1975. Ethology. New York : Holt, Rinehart \& Winston.

Eisenberg, J. F. \& Leyhausen, P. 1972. The phylogenesis of predatory behavior in mammals. $Z$. Tierpsychol. 30, 59-93.

Ewer, R. F. 1963. The behavior of the meerkat, Suricata suricatta (Schreber). Z . Tierpsychol. 20, 570607.

Ewer, R. F. 1967. The behaviour of the African giant rat (Cricetomys gambiamus Waterhouse). $Z$. Tierpsychol., 24, 6-79.

Ewer, R. F. 1968. Ethology of Mammals. New York: Plenum Pub. Co.

Fagen, R. M. 1976. Exercise, play, and physical training in animals. In: Perspectives in Ethology (Ed. By P. P. G. Bateson \& P. H. Klopfer), pp. 189-219. New York: Plenum Pub. Co.

Fox, M. W. 1969. Ontogeny of prey-killing behavior in canidae. Behaviour, 35, 259-272.

Fox, M. W. 1972. Socio-ecological implications of individual differences in wolf litters: A developmental and evolutionary perspective. Behaviour, 41, 298-313.

Groos, K. 1898. The Play of Animals. New York: D. Appleton.

Gustavson, C. R., Garcia, W. G., Hankins, W. G. \& Rusinak, K. W. 1974. Coyote predation control by aversive conditioning. Science, N.Y., 184, 581-583.

Knowlton, F. F. 1972. Preliminary interpretation of coyote population mechanics with some management implications. J. Wildl. Mgmt., 36, 369-382.

Kruuk, H. 1972. The Spotted Hyena. Chicago: University of Chicago Press.

Leyhausen, P. 1956. Verhaltensstudien an Katzen. Z. Tierpsychol., Beiheft 2, 1-120. (3rd edn, 1973).

Leyhausen, P. 1965. Über die Funktion der relativen Stimmungshierarchie (dargestellt am Beispiel der phylogenetischen und ontogenetischen Entwicklung des Beutefangs von Raubtieren). $Z$. Tierpsychol., 22, 412-494.

McFarland, D. J. 1971. Feedback Mechanisms in Animal Behavior. New York: Academic Press.

McFarland, D. J. \& Sibly, R. 1972. Unitary drives revisited. Anim. Behav., 20, 548-563.

Polsky, R. H. 1975a. Developmental factors in mammalian predation. Behav. Biol., 15, 353-382.

Polsky, R. H. 1975b. Hunger, prey feeding, and predatory aggression. Behav. Bioi., 13, 81-93.

Poole, T. B. 1966. Aggressive play in polecats. Symp. Zool. Soc. Lond., 18, 23-44.

Rasa, O. A. E. 1973. Prey capture, feeding techniques, and their ontogeny in the African dwarf mongoose, Helogale undulata rufula. Z. Tierpsychol., 32, 449-488.

Schaller, G. B. 1972. The Serengeti Lion. Chicago: University of Chicago Press.

Symons, D. 1974. Aggressive play and communication in rhesus monkeys (Macaca mulatta). Am. Zool., 14. 317-322.

White, M. 1973. Descriptions of remains of deer fawn killed by coyotes. J. Mammal., 54, 291-293.

Wüstehube. C. 1960. Beiträge zur Kenntnis besonders des Spiel- und Beutefangverhaltens einheimischer Musteliden . Z . Tierpsychol., 17, 579-613. 